\title{
2006-495: VISUALIZATION IN CONSTRUCTION SCIENCE AND ENGINEERING EDUCATION
}

\section{Mohammed Haque, Texas A\&M University}

Dr. Mohammed E. Haque is the holder of Cecil O. Windsor, Jr. Endowed Professorship in Construction Science at Texas A\&M University at College Station, Texas. He has over fifteen years of professional experience in analysis, design, and investigation of building, bridges and tunnel structural projects of various city and state governments and private sectors. Dr. Haque is a registered Professional Engineer in the states of New York, Pennsylvania and Michigan, and members of ASEE, ASCE, and ACI. Dr. Haque received a BSCE from Bangladesh University of Engineering and Technology, a MSCE and a Ph.D. in Civil/Structural Engineering from New Jersey Institute of Technology, Newark, New Jersey. His research interests include fracture mechanics of engineering materials, composite materials and advanced construction materials, computer applications in structural analysis and design, artificial neural network applications, knowledge based expert system developments, application based software developments, and buildings/ infrastructure/ bridges/tunnels inspection and database management systems. 


\title{
Visualization in Construction Science and Engineering Education
}

\begin{abstract}
With the rising reliability and serviceability of IT technology in recent years, science, engineering, and technology classes have begun to vastly assimilate IT technology as an effective tool for classroom reform. The widening gamut of IT applications has come to include the development of web based "virtual learner-centered classrooms," allowing typical classrooms to reach more extensive student populations. As the archetypal engineering and construction science classroom is highly dependent on the instructor, developing students' critical thinking skills becomes a challenging task for even the most inspired of educators. Nonetheless, these skills are a continual necessity for any student planning to venture into the engineering or construction science profession. Despite the excellence of the various textbooks available for engineering students, the associated rigorous theories and rhetoric make it a tedious academic hurdle for numerous students. However, through the implementation of IT technology, theories are exemplified in a virtual environment--replacing the dullness of written theory with rich multimedia, animation, interactivity, virtual walk-through, and manipulated image visualization. These educational advancements substantially improve students' conceptual understanding. This paper demonstrates various design and construction visualization techniques that would act as critical improvements in the educational sphere of the typical engineering and construction science classrooms. Technologies such as image visualization/ animation, virtual reality image manipulation, design animation, and walk-through virtual navigation are exhibited throughout this paper. These techniques, demonstrated through virtual construction models of steel structures, can potentially be valuable tools not only in the classroom, but also as effective self-directed tools for open learning by facilitating the expansive power of the World Wide Web.
\end{abstract}

\section{Introduction and Background}

The traditional methods of classroom teaching are often supplemented by alternative methods, to enhance the understanding of the students. These include field trips, use of 3D drawings and physical models. Although field trips are the best way to expose students to actual construction methodologies and sequences, they present difficulties of logistics and cost. Besides, the site may not be at a particular stage of construction, or the construction may not be fast enough to explore the various aspects of the process within a short duration of time ${ }^{1}$. In addition, the risks involved in field trips may be a deterrent in arranging more site visits for the students by the educational institutions.

Although the traditional methods of instruction are very effective in explaining the principles of structure to students, they have limitations that often make their use for instructional purposes unviable. Haque ${ }^{2}$ is of the view that traditional lecture format teaching methods sometimes fall short of conveying the complex analysis and design principles that need to be mastered in structural design. Enhancing World Wide Web developments, the new opportunities for interactivity and flexible access to various media format (text, sound, static illustrations, 2D and 
3D dynamic illustrations, Virtual Reality worlds) challenge the traditional experience in shaping learning environments for web-based education.

It is essential to use alternative modes of instruction to create an 'almost real' environment which enables students to better understand the construction concepts. In today's computer age, it is crucial to use multimedia as effective tools of teaching. Kuyath ${ }^{3}$ is of the view that if complex topics were explained through animations, multimedia, and interaction, student understanding would be greatly improved. 3D models created using software like Autodesk Viz, Architectural Desktop, and Autodesk 2005 produce life like images in the virtual world with its rendering capabilities using parameters like lighting, material, textures, etc. For the net savvy generation of today, this form of multimedia form essential tools that can be utilized for effective teaching. 3D models created in software like AutoCAD and rendered in Autodesk Viz can produce life like images with various tools available within them. VRML's can be used in addition to regular 3D models to better explain complex construction details. Unlike conventional 3D modeling, VRML presents no problem of selecting a viewpoint to understand a model, since one can freely choose a viewpoint. In VRML, it is possible to animate the objects in the scene like in traditional animation but the user can watch the animation from whatever viewpoint he wishes ${ }^{4}$. This is a valuable resource, which can help students understand the various aspects of construction technology due to its inherent nature of being interactive and graphical.

Visualization has always been an important aspect in the construction industry and construction education has always laid stress on that aspect. Design professionals and educators used drawing as a practical tool for seeing, thinking and understanding their ideas, and for communicating them to others. In education, drawing was often woven tightly into curriculums and it was expected to play a major role in developing students' visual abilities ${ }^{5}$. With the advance of technology, 3D visualization has become very user friendly and objects that were restricted to drawings in paper can today be viewed in a 3D environment with ease. The Internet revolution has also changed the world of education with distance learning becoming a more convenient, accessible and lucrative.

Construction operations range from the relatively simple to the most complex. Kamat and Martinez ${ }^{6}$ are of the view that traditional methods used to design them prove ineffective in many cases where simulation modeling and visualization can be of substantial help. The purpose of using simulation to design construction operations is to obtain insights into alternate designs and thus help the planner make the most advantageous decisions ${ }^{7}$.

One of the focus areas in this technologically advancing era is to provide better visualization through the Internet. Lipman and Reed $^{8}$ are of the view that the ultimate goal is to provide threedimensional web based technologies for managing, accessing and viewing construction project information. In their research, they have tried to determine the applicability of Virtual Reality Modeling Language (VRML) in construction industry applications.

Classroom use of IT for teaching science, engineering and technology has increased dramatically in recent years and has proved to be very effective in various situations ${ }^{9-12}$. The student-centered distance-learning archetype should include dynamic demonstration of theoretical engineering 
models allowing students to manipulate, experiment, and translate theories into real-world applications ${ }^{10}$.

The objective of this research paper was to demonstrate various design and construction visualization techniques that would act as critical improvements in the engineering and technology teaching and learning environments. The interface, the graphical and the interactive nature of the entire system would enable students to explore, evaluate and gather information about the various construction techniques using their own curiosity and eagerness and thereby develop their self-learning process.

\section{Research Methodology}

Technologies such as image visualization/ animation, virtual reality image manipulation, design animation, and walk-through virtual navigation were demonstrated through a virtual construction model of a steel structure. Hot links were embedded within the virtual 3D model of the steel structure at the joints to pop-up VRML navigation windows for real-time views of steel joints. A flow chart for the virtual model construction sequence is shown in Figure 1.

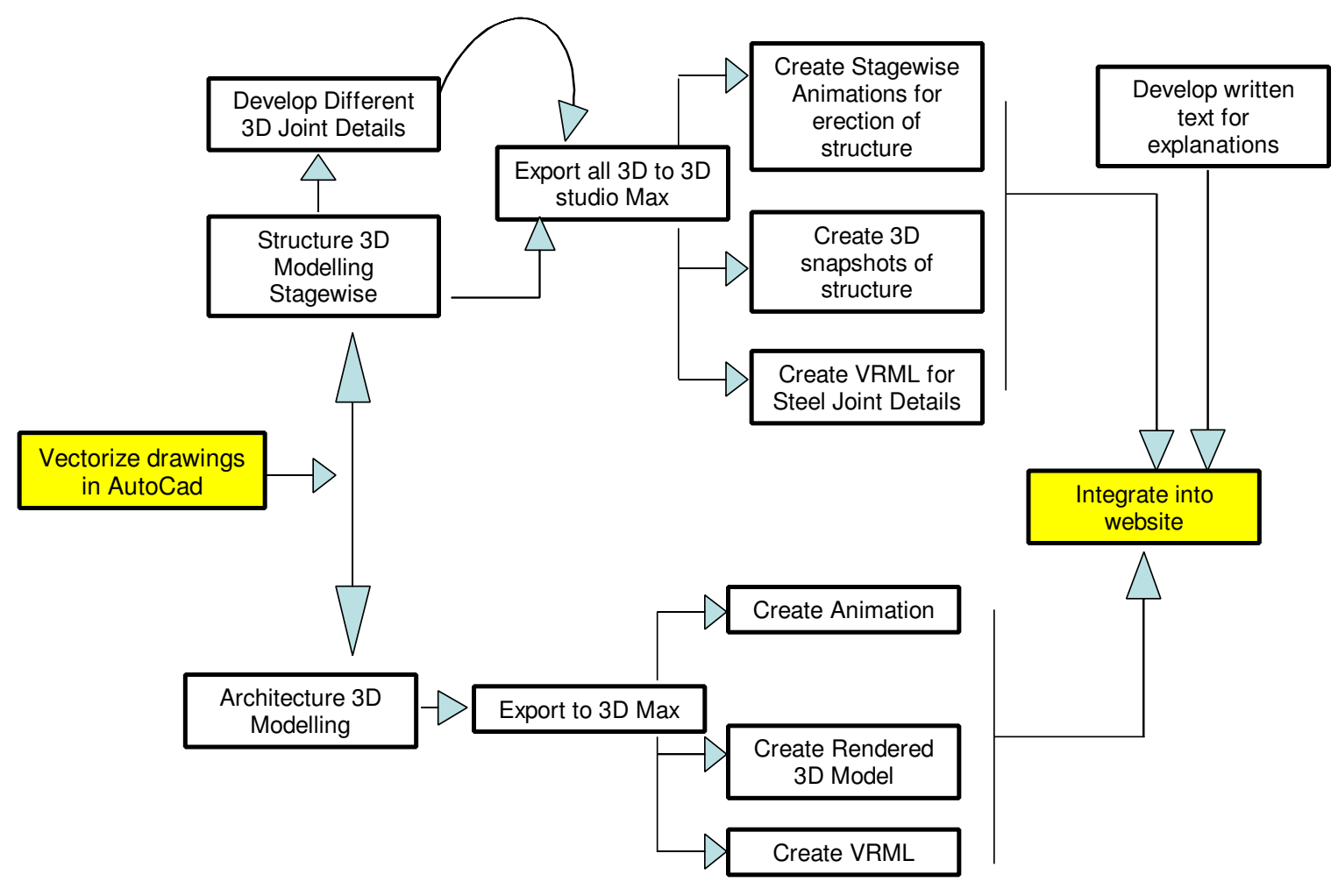

Figure 1: Flow chart 
3D models of the construction steps were developed in AutoCAD and exported to 3ds max for rendering and other finishing work (Figures 2 and 3).

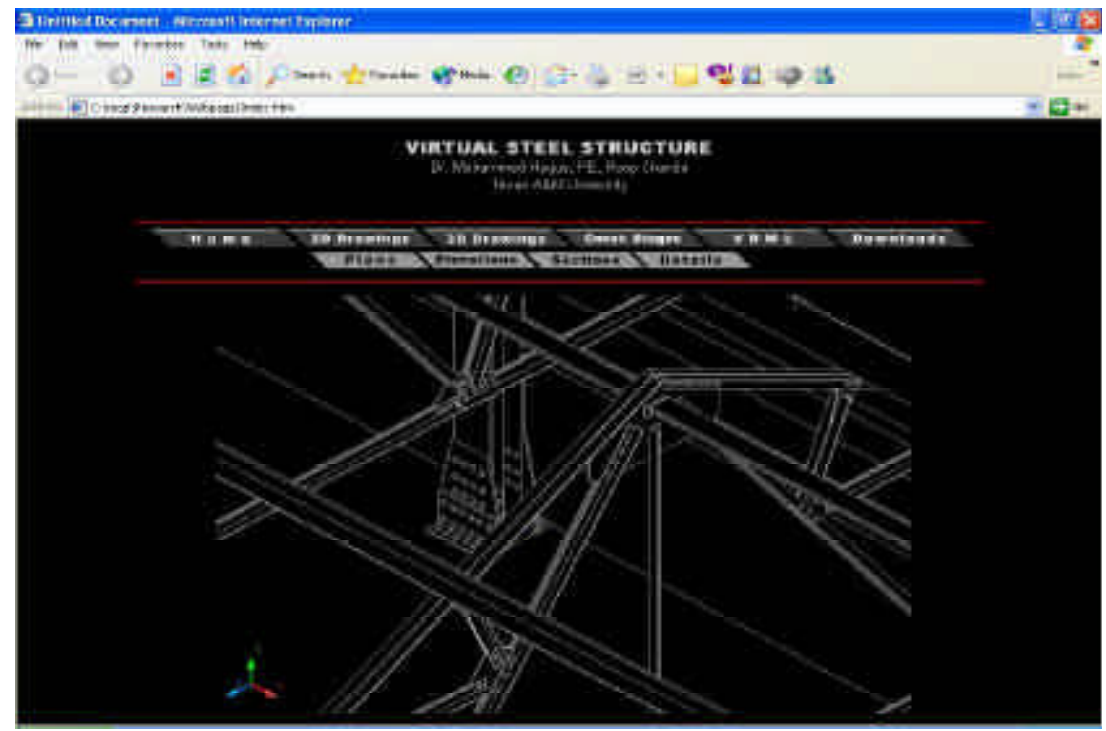

Figure 2: 3D AutoCAD model of steel joints

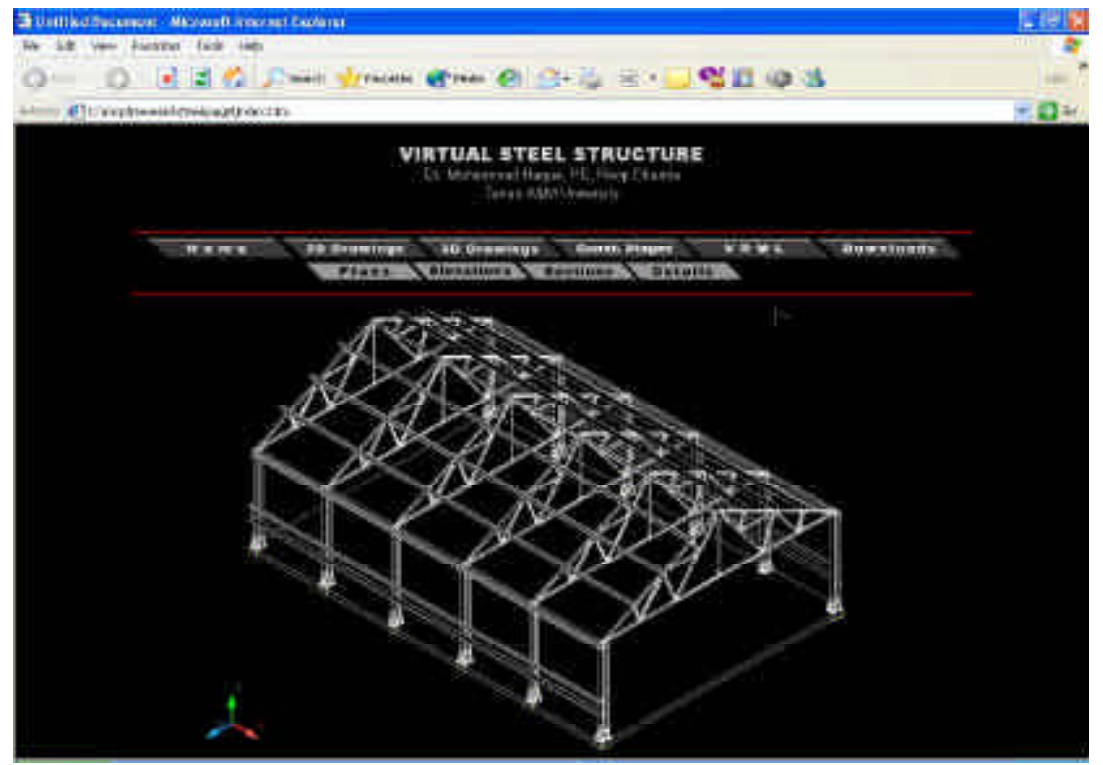

Figure 3: 3D AutoCAD model of structure

All the rendered models of the steel joints were exported to the VRML format for compatibility with the VRML browser. Similarly, VRML models were created for all joints for every sequence of construction (Figure 4). 

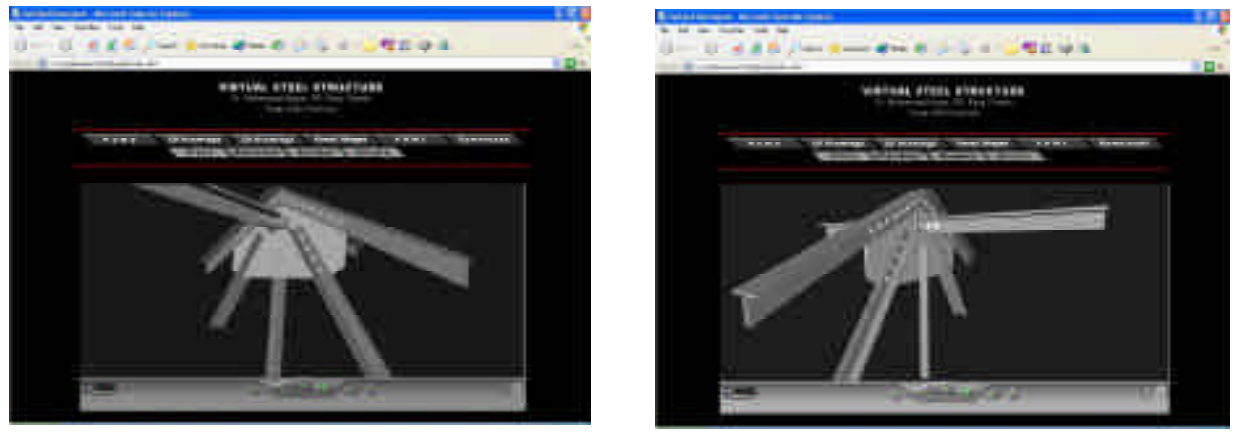

Figure 4: 3D images of truss joints on VRML browser from different angles

In order to teach steel joint design, 3D computer animations were developed to show magnified details of steel joints and all the possible modes of failures due to various forces. These animations were created using 3D Studio Max with a provision to magnify and zoom in, to closely watch the phenomenon of the failure (Figure 5). These animations were simultaneously linked to the Excel spreadsheet based joint design calculations and design checks, for stepwise understanding of the complex computations. 3D model was then rendered and saved in *.avi file format to create movies that showed animated connection failure as the forces increased. 3D model was exported to Macromedia Director to create a real time 3D environment (Figure 6). Macromedia Director MX enabled to create real-time 3D environments to demonstrate a variety of scientific concepts. The Macromedia W3D exporter allowed the artwork in 3D Studio Max, and easily exported the files into a format that worked well with Director.

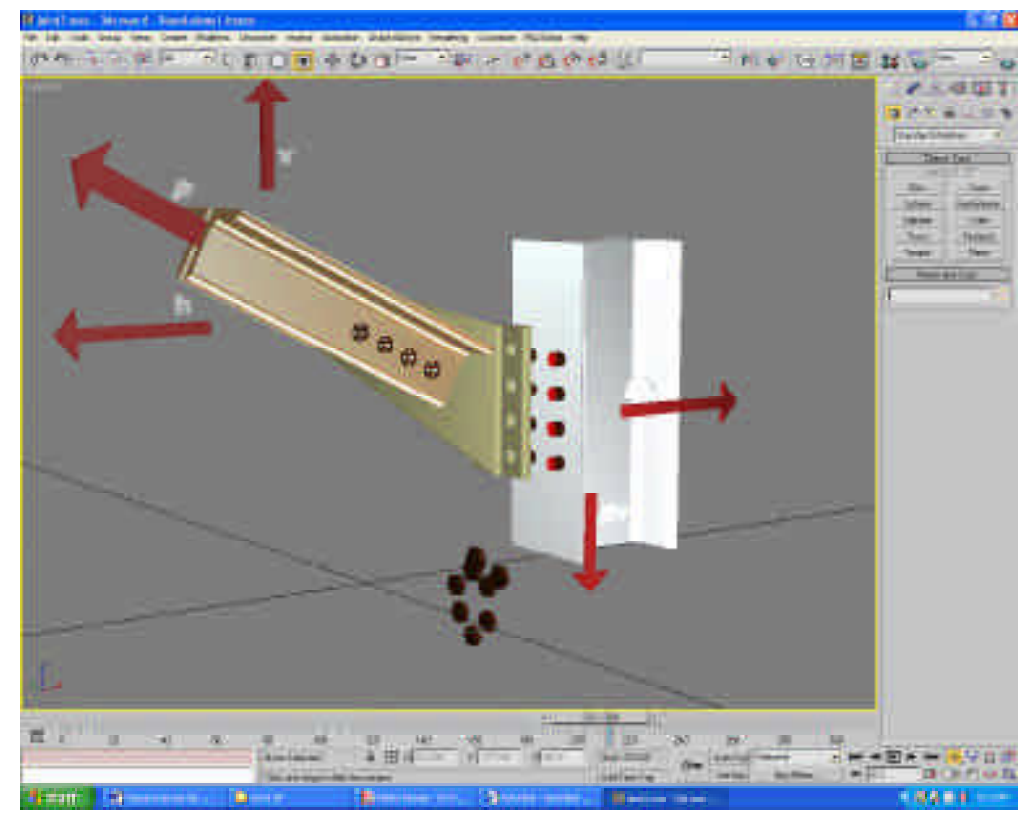

Figure 5: 3D Model after setting frames to generate animations 


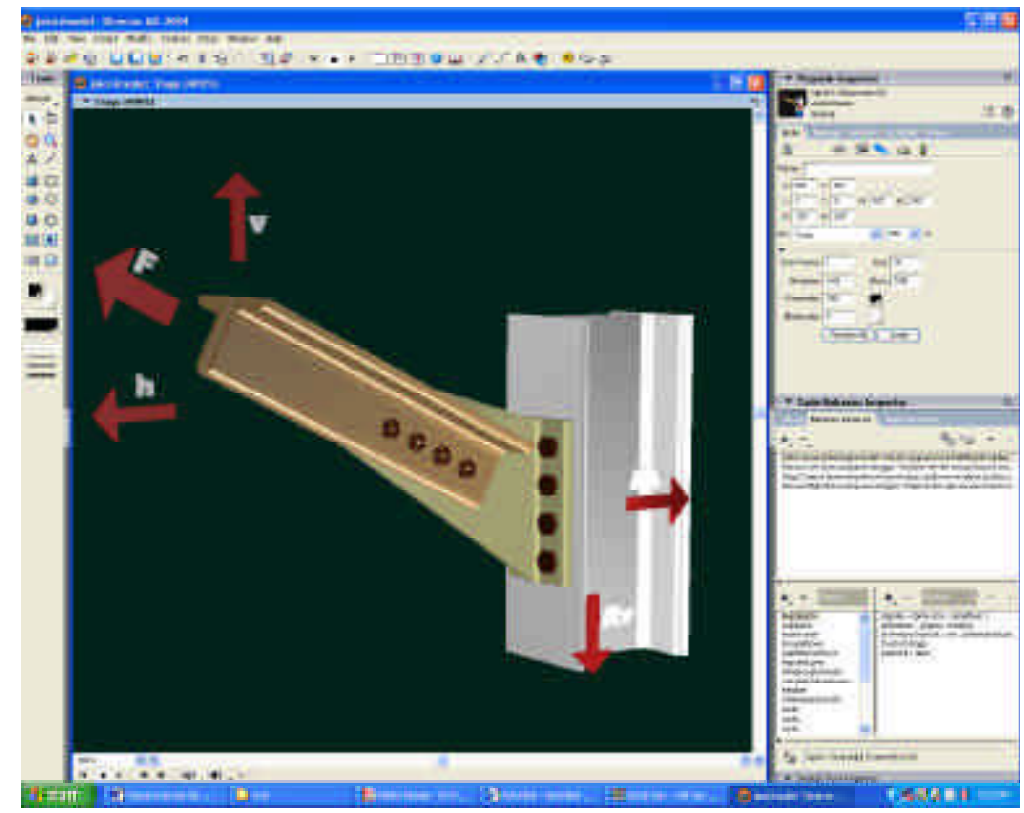

Figure 6: 3D models when exported to Macromedia Director

Once the 3D models, VRML and walkthrough animations were completed, the final step was to integrate the entire work making it a web based, comprehensive, interactive learning tool for the students. This was developed using Macromedia Dreamweaver. This software helped web page development and hosted all files from MS Excel, MS Power Point, Macromedia Director, Macromedia Flash, VRML, 3D Studio Max rendered animations and all other software used in this research. The interface essentially provided the interactive environment that enabled the students to navigate through the various aspects of the construction details.

On the 3D model, which explained the structural layout of the building, hyperlinks or 'hot spots' were provided at certain key locations, which opened in new windows and displayed the interactive VRML's of those details. The student can navigate the model using the VRML model and explore it from different angles providing more information regarding the construction technique and design philosophy.

\section{Concluding Remarks}

This paper describes a 3D model of steel structure and design details, and place them in a virtual world using AutoCAD, 3ds MAX, VRML, Macromedia Director, Macromedia Flash and Macromedia Dreamweaver. The model shows the construction sequence of a steel framed structure virtually. The model also makes it possible for viewing steel joints by rotating it or zooming into it in a real-time virtual 3D environment. 3D images are popular among instructors to present processes and details in a more interesting fashion. With this research, the attempt was to make the presentations even more interactive in which students could play around with to get 
a better understanding using animations. Considering the interest of youths in computer games these days the use of a 3D computer animation model will develop higher interest and will motivate them to further understand and retain important concepts of design and construction of steel structure. These visualization techniques can be valuable aids for not only teaching engineering and technology in the classroom but as an effective self-directed tool for open learning by facilitating the expansive power of the World Wide Web.

\section{References:}

1. Haque, M.E., Aluminumwala, M (2004) A virtual tour of a Reinforced Concrete Building Construction. Paper presented at the American society for Engineering Education conference. Paper retrieved Jan 28, 2005, from http://asee.org/about/events/conferences/searchResults.cfm?searchMode=paperAuto $\mathrm{r} \&$ searchText $=$ murtuza\&search $=$ Search\&searchYears $=2004 \% 2 \mathrm{C} 2003 \% 2 \mathrm{C} 2002 \% 2 \mathrm{C}$ 2001\%2C2000\%2C1999\%2C1998\%2C1997\%2C1996

2. Haque, M.E. (2001) Web based visualization techniques for structural design education. Paper presented at the American society for Engineering Education conference. Paper retrieved Jan 28, 2005, from http://www.asee.org/conferences/search/01143_2001.pdf.

3. Kuyath, S (2002) How computer animations make teaching complex topics more effective and more efficient. Proceedings of the 2002 American Society for Engineering Education Annual Conference \& Exposition. Retrieved Jan26, 2005, From http://asee.org/about/events/conferences/searchResults.cfm?searchMode= paperAuto r\&searchText=kuyath\&search=Search\&searchYears=2002

4. Jonkers, Hugo (2000) “On the use of VRML in Educational Software. Experiences from the project: JIMM Problem Solver. Future Generation Computer Systems. September 2000: 49-53.

5. Anderson, E (2002) Enhancing Visual Literacy through Cognitive Activities. Paper presented at the 2002 ASEE/SEF/TUB Colloquium, American Society for Engineering Education. Retrieved Jan23, 2004, from http://www.asee.org/conferences/international/papers/anderson.pdf

6. Kamat, V. R., and Martinez, J. C. (2001) Visualizing Simulated Construction Operations in 3D, Journal of Computing in Civil Engineering, Vol. 15, No. 4, American Society of Civil Engineers, Reston, VA, 329-337.

7. Kamat, V. R., and Martinez, J. C. (2000) 3D Visualization of Construction Processes and Products, Proceedings of CIT2000 - The CIB-W78, IABSE, EG-SEA-AI International Conference on Construction Information Technology, Reykjavik, Iceland, 506-512. Retrieved Jan23, 2004, from http://www-personal.engin.umich.edu/ vkamat/publications.htm

8. Lipman, R. \& Reed, K. (2000) Using VRML in construction industry applications. Paper presented in Web3d VMRL 2000 Symposium.

9. Haque, M. E., Saherwala, S. (2004) 3-D Animation and Walkthrough of Design and Construction Processes of Concrete Formworks. Paper presented at the 2004 ASEE Annual Conference. Paper retrieved Aug 27, 2004 from http://www.asee.org/acPapers/2004-438_Final.pdf

10. Haque, M.E. (2001) Web based visualization techniques for structural design education. Paper presented at the American society for Engineering Education conference. Paper retrieved Jan 20, 2004, from http://www.asee.org/conferences/search/01143_2001.pdf

11. Haque, M.E. (2003) Visualization Techniques for Structural Design Education. Proceedings of the American Society for Engineering Education, 2003 ASEE Annual Conference. Paper retrieved Nov 20, 2005, from http://md1.csa.com/partners/viewrecord.php?requester=gs\&collection=TRD\&recid $=2005078024806 \mathrm{CE} \& \mathrm{recid}=2005078031035 \mathrm{MT}$

12. Haque, M.E., "Desktop Virtual Environments in Construction Education," Proceedings of the SIGRADI'05 IX Iberoamerican Congress of Digital Graphics, pp. 712-730, ISBN: 1-59975-306-5, November 21-23, Lima, Peru. 